\title{
How do Crystals Grow? Steno’s Approach
}

Citation: S. Menchetti (2021) How do Crystals Grow? Steno's Approach. Substantia 5(1) Suppl.: 77-87. doi: 10.36253/Substantia-1279

Copyright: (c) 2021 S. Menchetti. This is an open access, peer-reviewed article published by Firenze University Press (http://www.fupress.com/substantia) and distributed under the terms of the Creative Commons Attribution License, which permits unrestricted use, distribution, and reproduction in any medium, provided the original author and source are credited.

Data Availability Statement: All relevant data are within the paper and its Supporting Information files.

Competing Interests: The Author(s) declare(s) no conflict of interest.

\author{
Silvio Menchetti \\ Dipartimento di Scienze della Terra, Università di Firenze, Italy \\ E-mail: silvio.menchetti@unifi.it
}

\begin{abstract}
Steno (1638-1686) operated in a historical context rich in discoveries and observations done by previous scientists such as Vannoccio Biringucci, Georg Bauer (Agricola), Johannes von Kepler, Robert Hooke, Christiaan Huyghens, Erasmus Bartholin, and others. Steno also had to fight against some irreducible dogmatic and "mythological" beliefs, such as the vis formativa and succus lapidescens, supported by e.g. Michele Mercati and Anselmo Boetius de Boot, respectively. In De solido intra solidum naturaliter contento dissertationis prodromus Steno deals with almost all aspects of Earth Sciences and not just "solid inclusions" as it might seem from the full title of the Prodromus. This contribution deals only with aspects related to crystallography and minerals in general. The most famous is highlighted by the sentence "non mutatis angulis" which is a clear reference to the fact that interfacial angles of quartz crystals do not change regardless of the size and the number of the faces. This observation was then generalized as a law for all minerals by Jean-Baptiste Romé de l'Isle a century later. Less well known but of great importance is Steno's assertion that the crystals grow thanks to the addition of particles that come from an external fluid and are not "fed" from the inside like in vegetables; moreover, the speed of growth is not the same for all faces. For example, the faces of the "pyramid" in quartz can grow more or less rapidly than those of the prism (giving rise to either squat or elongated crystals). It can therefore be argued that Steno has greatly contributed to the concept of anisotropy in the solid state, typical of all crystals. Stenonite, $\mathrm{Sr}_{2} \mathrm{Al}\left(\mathrm{CO}_{3}\right) \mathrm{F}_{5}$, is a new mineral dedicated to his memory about sixty years ago.
\end{abstract}

Keywords: Steno, crystal growth, quartz, interfacial angles, stenonite.

\section{INTRODUCTION}

To introduce the topic of crystal growth and to highlight Steno's great contribution, it seems particularly fitting to report most of the first page from the foreword by O. Grubessi and F.P. Sassi, ${ }^{1}$ of the book "Minerals in stamps" by Grubessi and Pasero, published by the Italian Society of Mineralogy and Petrology in 1998.

Special stones and gems have written the history of Earth Sciences, and have accompanied the history of man with variegated roles.

${ }^{1}$ O. Grubessi, F.P. Sassi, in Minerals in stamps (Eds. O. Grubessi, M. Pasero), Felici Editore, Pisa, 1998, viii +215 pp. 

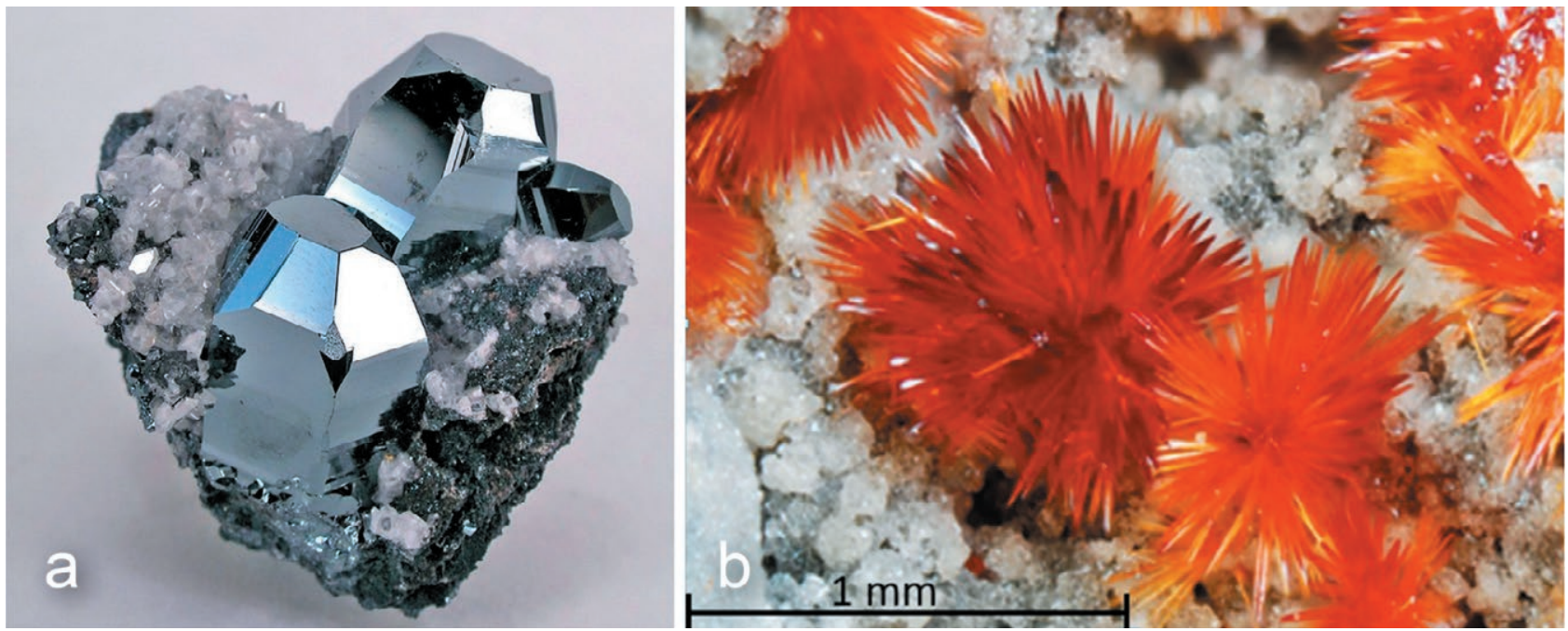

Fig. 1. Morphology and colour of minerals. 1a: Hematite Fe2O3 (https://www.mindat.org/photo-122270.html). 1b: Red and yellow crystals of cetineite $[(\mathrm{K}, \mathrm{Na}) 6 \mathrm{Sb} 3+12(\mathrm{Sb} 3+\mathrm{S} 3) 2 \mathrm{O} 18(\mathrm{OH}) 0.5 .5 \mathrm{H} 2 \mathrm{O}]$ (Collection V. Paoletti, photo by B. Fassina, published with permission).

Charm, curiosity, magic, science; mystic therapy, magic therapy, physical therapy; belief in extra natural powers and the belief in the action of the product, are intimately bound with the role that stones, minerals and gems, play in our heritage as well as in the mentality of our ancestors.

By his nature, man has always been attracted by what is beautiful, precious and mysterious. Therefore, his interest in gems and minerals, which often have all these features, is not surprising.

In the course of centuries the intrinsic value attributed to these stones has also been modified as a result of external factors. Indeed, their rarity and beauty became supplemented on one side by their process, as an expression of human activity and intelligence, and on the other side, by their links with astrology and medicine, as an answer to transcendental requirements.

However, the attraction man has for minerals prevails over all the other features in human feelings, a kind of fascination which has not been the least extinguished by the development of scientific knowledge about their structure, properties, and genesis.

The well-shaped morphology, the beauty of minerals in general, the flatness and the shine of the faces (Fig. 1a), the color that can vary greatly even for the same species (Fig. 1b), were certainly some of the many observations on minerals that triggered human curiosity. While most people have limited themselves to expressing wonder and amazement, some have wondered what could be the source/origin of such peculiarities shown by natural objects. What are the relationships between what we can see with the naked eye and what is inside the crystal and which we cannot see? What are the rea- sons for the variability of shapes, color, luster, hardness? In conclusion, how do crystals form and grow?

When Steno lived in Tuscany he made many observations on the formation and growth of crystals as it can be understood from his De solido intra solidum naturaliter contento dissertationis prodromus. ${ }^{2}$ Actually Steno was not the first one to deal with these problems, as reported in the next section where some of the pioneers of this long history will be mentioned.

\section{THE BIRTH OF CRYSTALLOGRAPHY}

In this brief historical excursus, the text by A. Authier $^{3}$, Early Days of X-ray Crystallography, published in 2013 , to celebrate the international year of crystallography (2014), will be of great benefit.

By personal and perhaps questionable choice let's begin from the early 1500s, more precisely with Vannoccio Biringucci or Biringuccio (1480-1537) from Siena. Biringuccio was a great technician who strongly contributed to the literature related to mineralogy and metallurgy of the XVI century.

His work De la Pirotechnia (Fig. 2), written in Italian, was published posthumously in 1540. In the ten books that compose it, Biringuccio deals with minerals and mostly with melting, separating and alloying of

\footnotetext{
${ }^{2} \mathrm{~N}$. Stenone, Su un corpo solido contenuto naturalmente entro un altro solido. Prodromo a una dissertazione. A cura di Annibale Mottana, Edizioni Teknos, Roma, 1995, $66 \mathrm{p}$.

${ }^{3}$ A. Authier, Early days of X-ray crystallography, Oxford University Press, Oxford, 2013, 464 p.
} 


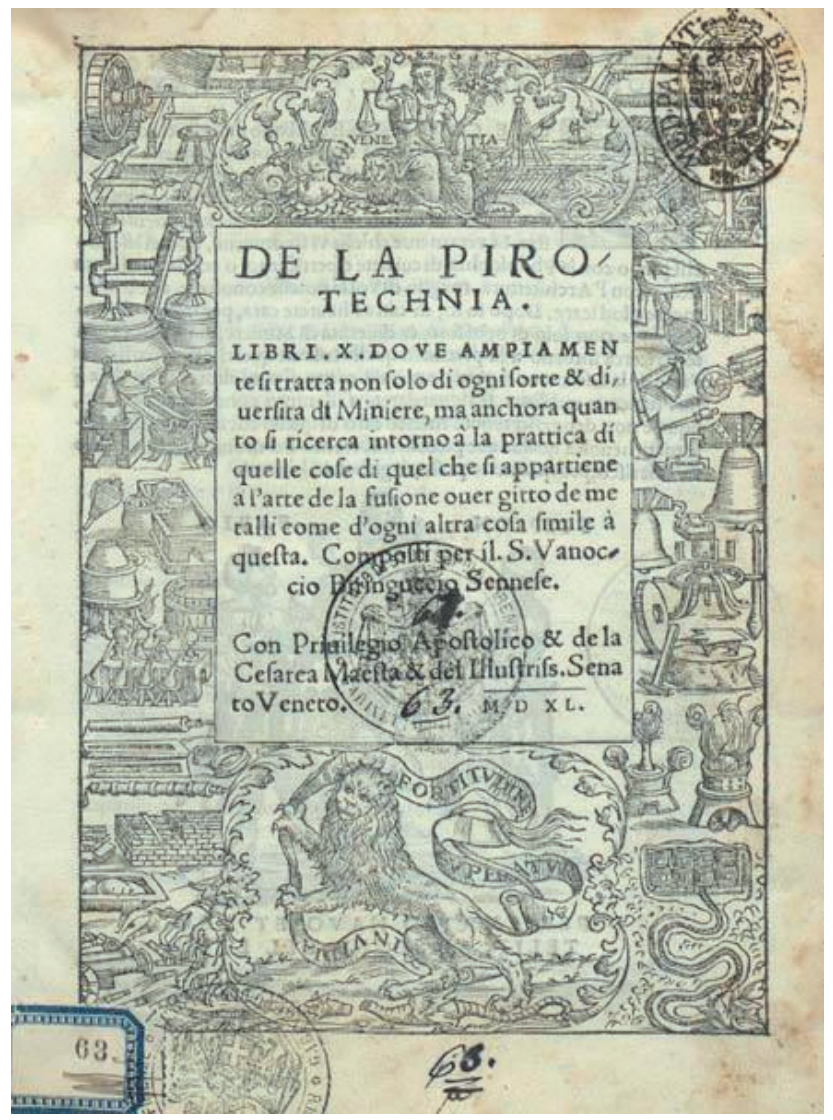

Fig. 2. Title page of De la Pirotechnia, published in Venice in 1540 (https://bibdig.museogalileo.it/Teca/ImageProvider?image $=. / 000 / 00$ 0/302/302960/302960_00005r.jpg).

metals. De la Pirotechnia, repeatedly printed and translated into French, English, Spanish and German, had great success especially for its eminently practical aspect. As far as mineralogy and crystallography are concerned, we report (Biringucci ${ }^{4}, 1914$ p. 187-188) his observation on the morphology of "margassite" (pyrite): "may be found as veins and in form of certain grains, either big or small, all cubic similar to dices, or alternatively prismatic all exactly squared so that no craftsman, with any instrument he uses, could not draw more perfect nor better their angles". In modern terms (see the Italian textbook Carobbi, Mineralogia, $1^{5}$ p. 5) this sentence can be expressed as "pyrite occurs in crystals in the shape of a geometrically regular cube but also in the shape of a straight parallelepiped, with dihedral angles between pairs of faces always equal to $90^{\circ}$. . As an example, Fig.

${ }^{4}$ V. Biringucci, De la Pirotechnia, a cura di Aldo Mieli, Società Tipografica Editrice Barese, Bari, 1914, 198 p.

${ }^{5}$ Carobbi, Mineralogia 1. I Fondamenti di Cristallografia e Ottica Cristallografica by F. Mazzi and G.P. Bernardini USES, Firenze, 1983262 p. 3a shows geometrically regular pyrite cubes with square faces, while in Fig. 3b the faces of the pyrite "cubes" are rectangles. But the interfacial angles are always $90^{\circ}$. As it is known, interfacial angles are important in crystallography but not the extension and regularity of the faces. This is the first qualitative reference to what will become the law of the constancy of interfacial angles expressed as a general law by Jean-Baptiste Romé de l'Isle in 1783 . As we will see, Steno also contributed to this point.

Georg Bauer (1494-1555), a doctor, also read and appreciated Biringuccio's work. He is better known by the Latinized name Georgius Agricola. Agricola (Fig. 4) obtained the Baccalaureus Artium at the University of Leipzig and later studied medicine. He also studied at the Universities of Bologna and Padua and developed his interest in the mineral world especially during his stay as a doctor in the mining town of Joachimstal (Jáchymov, Bohemia) and later in Chemnitz, Saxony. He was a person of great culture who left several treatises written in Latin including:

- Bermannus (remarkable knowledge on mining), 1530.

- De Natura fossilium (systematic mineralogy work), 1546.

- Rerum metallicarum interpretatio (mineralogical glossary in Latin and German), 1546.

- De re metallica, 1556 (summa of the knowledge of the time in metallurgy and mining), which obscured the fame of Biringuccio's Pirotechnia.

Agricola is often considered the "father of mineralogy".

Interesting information on Biringuccio and Agricola and on the relationships between their works (De la Pirotechnia and De re Metallica) can be found in the paper Origins of Mineralogy: the age of Agricola by C. Schneer $\left[6^{6}\right]$.

Other contributors practically contemporary to Steno's Prodromus are discussed below.

Johannes Kepler (1571-1630), was the first to postulate a correlation between the external morphology and the internal structure of crystals. In his 24-page pamphlet, Strena seu de nive sexangula, "A new year gift of hexagonal snow" he describes snow crystals as the result of the aggregation of water spheres of equal size which, interacting with each other, reach equilibrium, arranging themselves in regular hexagons. Studies

${ }^{6}$ C. J. Schneer, Eur. J. Mineral. 1995, 7, 721-734.

${ }^{7}$ J. Kepler, Strena seu de Nive Sexangula, Frankfurt am Main, Gottfried Tampach, 1611. English translation: C. Hardie with essays by B.G. Mason and L.L. Whyte, The six-sided snowflakes, Oxford University Press, Oxford, 1966. 

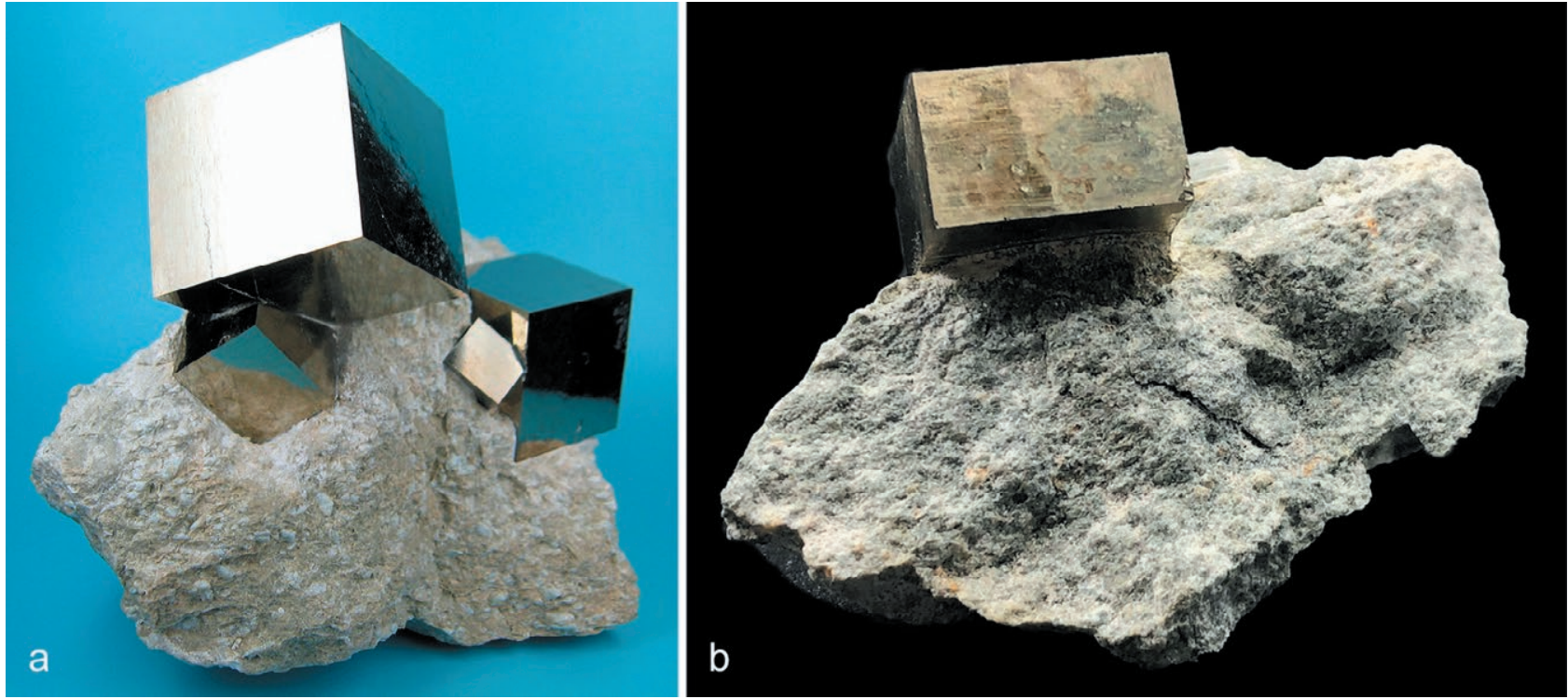

Fig. 3. Crystals of pyrite. 3a: Pyrite in geometrically regular cubes (https://en.wikipedia.org/wiki/Pyrite). 3b: "Cubes" of pyrite with rectangular faces (https://i.etsystatic.com/16351195/r/il/5994c7/1719730471/il_fullxfull.1719730471_rcxj.jpg).

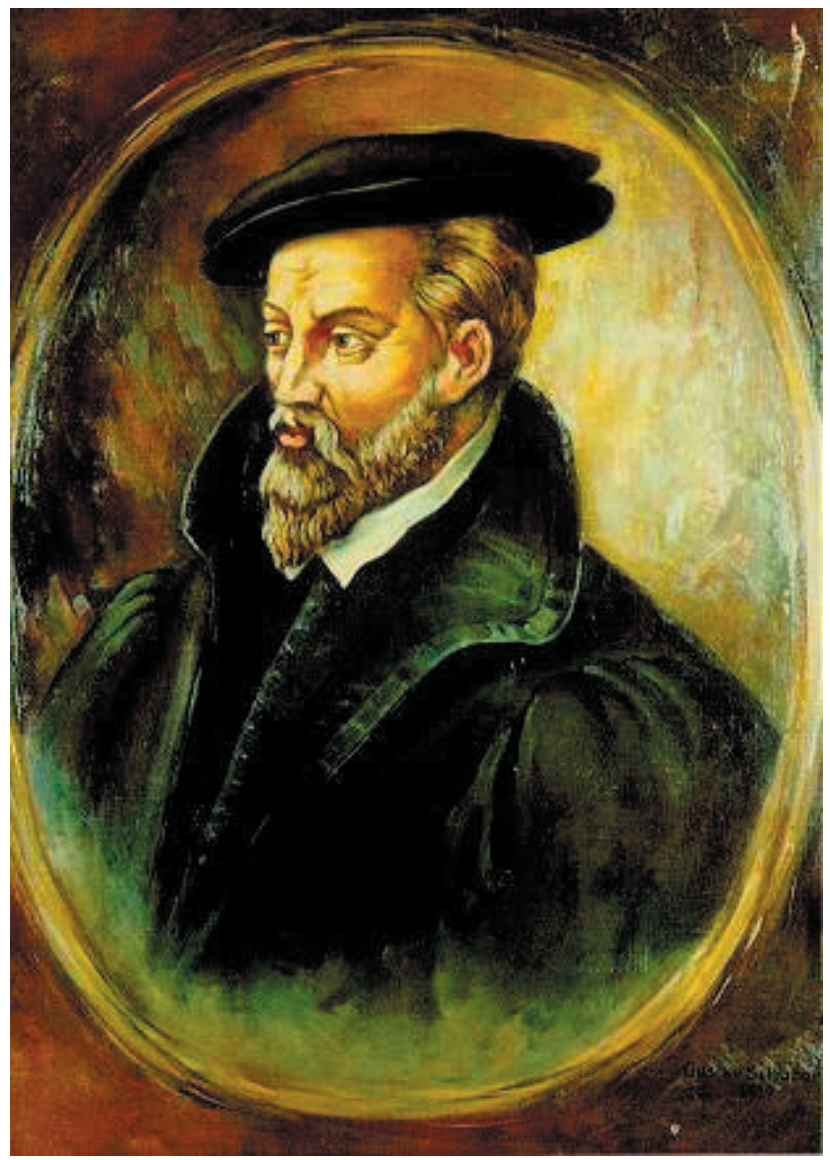

Fig. 4. Portrait of Georgius Agricola (unknown painter, https:// commons. wikimedia.org/w/index.php?curid=4858286). of snowflakes led Kepler to formulate the idea of close packing of spheres. The so-called Kepler conjecture, only recently demonstrated ${ }^{8}$, tells us that there is no way to arrange equal spheres in space with a density greater than that of the hexagonal close packing or the cubic close packing, with centered faces. According to Authier [3] (p. 372), Kepler's intuition is a milestone for the concept of the space lattice.

Robert Hooke (1635-1703), contributed to the emerging science of crystallography by developing pioneering models to deduce the distribution of the atoms' disposition in the structures from the shape of macroscopic crystals. For example, by variously combining identical spheres (close packing), he had managed to reproduce the external shape of alum octahedra (Fig. 5). According to Hooke ${ }^{9}$, by combining the equilateral triangle (A) and the square (L) (Fig. 5), one can reconstruct the shape of vitriol, quartz, saltpeter etc. Authier [3] (p. 399) highlights that Hooke "had already implicitly observed the constancy of interfacial angles, noting the extension of crystal faces depended on the number of spheres added on each plane during the growth of the crystal."

Rasmus Bartholin (1625-1698 brother of Thomas, teacher of Steno) discovered a curious optical property

${ }^{8}$ T. Hales, M. Adams, G. Bauer and 19 others A formal proof of the Kepler conjecture, Forum of Mathematics, Pi, 2017, 5, e2, 29 pp., doi: https://doi.org/10.1017/fmp.2017.1

${ }^{9}$ R. Hooke, Micrographia, Jo Martin, and Ja Allestry, printers to the Royal, Society, London, 1665. 


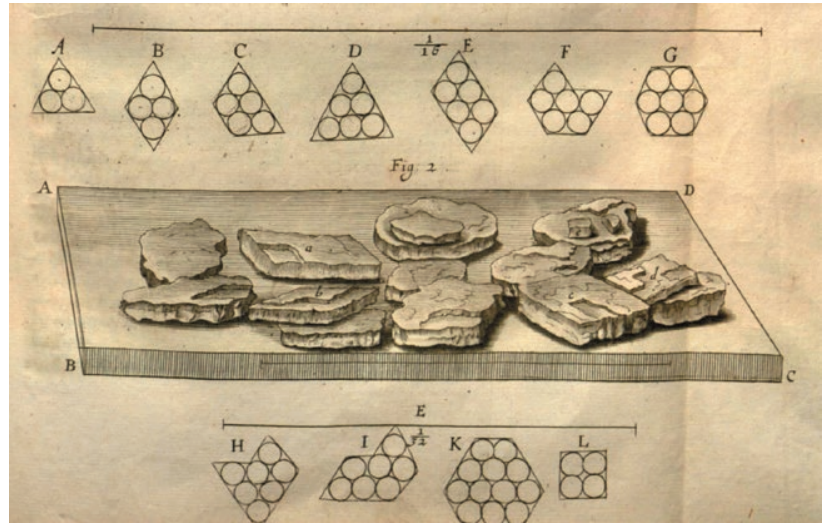

Fig. 5. Hooke's reconstruction of alum crystals by close packing of identical spheres. After Hooke, 1665 [9] (https://authors.library. caltech.edu/23510/1/BMC_Hooke\%27s_Models.pdf).

shown by transparent calcite crystals of Helgustaðir ("Icelandic spar") from eastern Iceland. A black dot marked on a sheet is doubled in two points when viewed through the faces of a calcite rhombohedron. The phenomenon was later identified and took the name of double refraction.

Christiaan Huyghens (1629-1696) formulated the theory of the wave nature of light useful to explain reflection and refraction phenomena. The phenomenon of double refraction was also explained with Huyghens' theory. He also assumed that calcite was made up of particles in the form of flattened ellipsoids of rotation, with the rotation axis parallel to the ternary axis of the rhombohedron. In this way he explained the rhombohedral cleavage of calcite.

Finally, Domenico Guglielmini (1665-1710), a mathematician, chemist and physician lived shortly after Steno. He was one of the first to take an interest in salt crystallization. In particular, in his articles, there are important observations on the morphology of crystals such as saltpetre, vitriol, rock salt and alum synthesized in the laboratory. Very interesting is Guglielmini's observation on rock salt cubes: although the shape of the crystals may be faulty "the inclination of the sides is always stable, which does not vary by one point from the right angle, typical of the cubic figure" (quoted in P. Aloisi, p. 167). It cannot be denied that the constancy of the angles for rock salt is clearly delineated. Guglielmini also contributed in an interesting way to the knowledge of the structure of crystals. In a well documented article entitled "Domenico Guglielmini e la Cristallografia", the author (P. Aloi$\mathrm{si}^{10}$ ) analyzes Guglielmini's writings in relation to the results of Biringuccio, Steno, Hooke, Huygens, Romé

${ }^{10}$ P. Aloisi, Periodico di Mineralogia, 1937, 8, 163-175. de l'Isle and Haüy and concludes “... without wanting to diminish the great merits of Romé de l'Isle and Haüy, it can be said, it seems to me, that a century before them, and in more difficult conditions, Guglielmini had already laid the fundamentals of crystallography" (P. Aloisi [10], p. 175).

\section{STENO}

Steno arrived in Italy in 1666 , preceded by his fame as a great expert in anatomy, but during the twoyear stay in Tuscany he also turned his interest to geology, mineralogy and crystallography. The Grand Duke involved Steno in various problems such as dissections of fish and human corpses, study and cataloging of fossils and minerals, geological excursions, etc. At the end of the two-year period he hastily wrote the famous Prodromus (Fig. 6), which was edited by his friend Vincenzo Viviani and published in 1669.

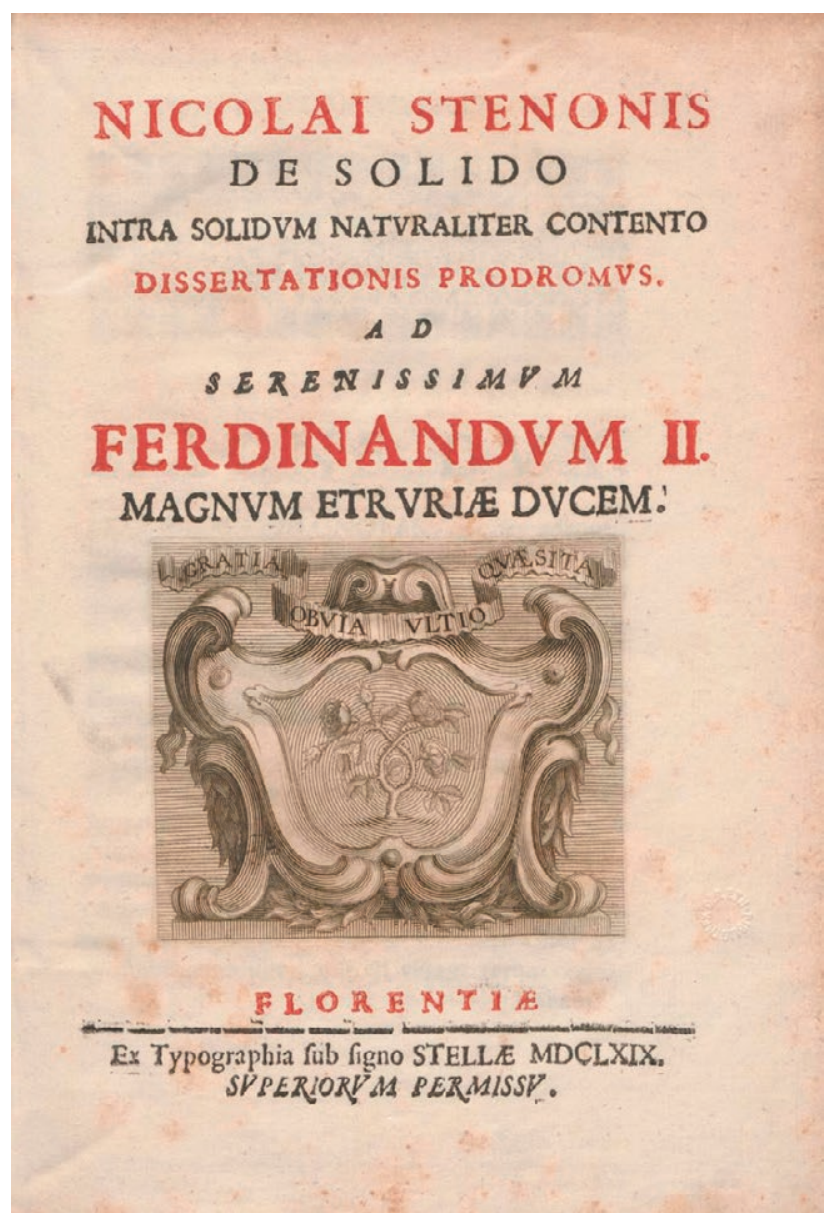

Fig. 6. Title page of Steno's Prodromus (Florentia: Ex typographiae sub signo Stellae, 1669). 
To conduct his research Steno could take advantage of the results previously achieved by e.g. Vannoccio Biringucci, Georgius Agricola, Johannes von Kepler, Robert Hooke, Christiaan Huyghens and Erasmus Bartholin but he also had to fight against a series of mythological beliefs, superstitions and dogmatic bonds. Particularly hard to believe, at least nowadays, the "vis formativa" for which fossils and minerals would form directly in the rocks by celestial influence ("principle" supported by e.g. Michele Mercati, 1541-1593) or the "succus lapidescens", petrifying juice that caused diamonds to reform in their fields a couple of years after they were removed ("principle” supported by e.g. Anselmo Boetius de Boot, 15501636). Michele Mercati and Anselmo Boetius de Boot were very influential, because they were the personal physician of the pope and of the emperor, respectively.

After a preamble of dedication to the Grand Duke and an illustration of the Prodromus content, Steno lists a series of almost dogmatic declarations. Only those most relevant to the present topic are reported here.

1. A natural body is made up of imperceptible particles accessible to the actions coming from magnet, fire and sometimes light; you can find free passages both between the particles and inside them (Stenone [2], p. 9). It seems very likely that Steno thought of particles juxtaposed to form a solid and was far from the intuition of a homogeneous-discontinuous-periodic sequence of atoms.

2. Distinction between fluid (moving particles) and solid: the particles never move away from each other "for as long as that solid remains solid and intact" (Stenone [2], p. 9). But "when a solid is formed, its particles move from one place to another" (Stenone [2], p. 9).

Steno was very interested in the problem of the movement of particles; in fact, he promised to analyze in detail the various causes of motion in the proposed Dissertation but which never was published. However, even in the Prodromus the exposition of the problem is very detailed and sometimes a little dispersive. After long discussions, which also acknowledge the existence of a divine force, he concludes that the movement of the particles in what is produced by Nature derives from the movement of a fluid that enters it. This fluid can come from the Sun or other source. (Stenone [2], p. 9-10).

Evidently Steno follows Descartes on the cosmic ether spread throughout the universe. As we know, this mysterious entity was thought to exist until the early twentieth century.

3. The sequential order of solid formation is defined (see the full title of the Prodromus). For example, fossils are formed before the rocks that contain them; mineralized veins are formed subsequent to the embedding rocks (Stenone [2], p. 12). This statement is based on Steno's principle of molding as explained by Kardel. ${ }^{11}$

4. Bodies with the same shape and intrinsic characteristics will be equal also as regards the place of formation (a somewhat risky statement, as observed by A. Mottana in Stenone [2] (p. XI), and the way they grow (Stenone [2], p. 13). Quartz and saltpeter are both formed by deposition from a fluid that is not necessarily aqueous (molten e.g. for quartz). In this regard it is worth mentioning a paper by $\mathrm{F}$. Rodolico ${ }^{12}$ relating to the "Cristalli di quarzo descritti da Nicola Stenone". Interesting observations by Steno are reported on the mixed inclusions present in the quartz crystals. Steno says that many inclusions are made up of only air and therefore quartz cannot have formed from a water fluid because otherwise all inclusions would be water and it is known "that the water thus contained cannot evaporate for any series of centuries" (Stenone [2], p. 26).

5. A natural body is always produced by a fluid (Stenone [2], p. 14); at present we know that this is not always true for some metamorphic minerals.

6 . The growth of a solid occurs by juxtaposition of particles precipitated by an external fluid and not by "digestion from within" as in a vegetable (Stenone [2], p. 14) (see below).

This is a concept of great importance in Steno's scientific thought.

\section{Crystal (Quartz) (Stenone [2], p. 25-30)}

To continue our discussion of Steno's crystallographic approach, we should focus on the mineral quartz. Steno prefers the term crystal, used by Pliny, to quartz, adopted by Agricola. It was believed that the clear and transparent quartz crystals, common in the mountains, were formed by a sort of super cooling of "permanently hardened" water. Of course Steno is against this hypothesis, as can be seen from the sentence "On the basis of what has been exposed so far, it would be legitimate to demonstrate that extreme cold is not the efficient cause of crystal (quartz)" (Stenone [2], p. 30). Steno's use of the words, "efficient cause" is very interesting. As we know, Aristotle asks himself the following question: Why do things arise, grow and die? He identifies four categories of causes in this regard: material, formal, efficient (or moving cause of a change or movement), and final. It is

\footnotetext{
${ }^{11}$ Troels Kardel, "Prompters of Steno's geological principles: Generation of stones in living beings, glossopetrae and molding," in The Revolution in Geology from the Renaissance to the Enlightenment (Ed. G. D. Rosenberg), Geological Society of America, Memoir 203, 2009 Boulder, CO., pp. 127- 134

${ }^{12}$ F. Rodolico, Rivista Storia Scienze Mediche e Naurali, 1955, 1-6.
} 
therefore evident that even in the 17th century, the Aristotelian categories were still influential.

According to Steno, crystal (quartz) is composed of two hexagonal pyramids, (we know that instead it is the combination of two rhombohedra, direct and inverse) and an equally hexagonal intermediate column that is the hexagonal prism. It is strange that a keen observer like Steno never mentions the little faces of the trapezohedron and of the trigonal bipyramid, which are very useful in distinguishing the right from the left quartz. Yet he must surely have seen them in the numerous quartz samples at his disposal.

After specifying the terms that he uses to describe the crystalline form, he goes on to explain the model of crystal growth that occurs by juxtaposing particles from an external fluid.

a) The crystal grows from an initial germ (on whose nature Steno declares himself incompetent) by juxtaposition of particles precipitated by an external fluid. Steno rejects growth by addition within the crystal as would be the case for growth of living things. (Stenone [2], p. 27). This "vegetative" principle recalls the ancient beliefs on mineral deposits whose arrangement was compared to that of the blood veins in the bodies of animals or to the branches of trees in the woods. Since a mineral deposit was thought to have formed inside a mountain, it was compared to a large branching tree with roots at the base of the mountain.

b) The particles are not distributed randomly on all planes (faces of the crystal) but, first on the apexes, then on the "pyramidal" faces, and then on the faces of the column (hexagonal prism). Therefore, the faces of the hexagonal prism (quadrilateral planes, constituted by the bases of the "pyramidal" faces) are sometimes large, sometimes small or completely missing (Fig. 7a and 7b). (Stenone [2], p. 27).

Furthermore, the quadrilateral planes are often striated for the same reason (Fig. 8).

c) The crystalline matter is superimposed on the various "pyramidal" faces at different times and in different quantities: therefore the "pyramid" axis does not always form the same straight line with the column axis (see Fig. 12, section 4). The faces of the "pyramids" are hardly equal to each other, and not always triangular (Stenone [2] 1995 p. 27) (Fig. 9) while the intermediate planes (faces of the hexagonal prism) are not always equal to each other and are not always quadrilateral. The solid angle of the vertex can be broken down into numerous solid angles so as to appear as an edge (Stenone [2], p. 27) (Fig. 9).

d) It may happen that the crystalline material does not spread evenly on the faces of the "pyramids" and the
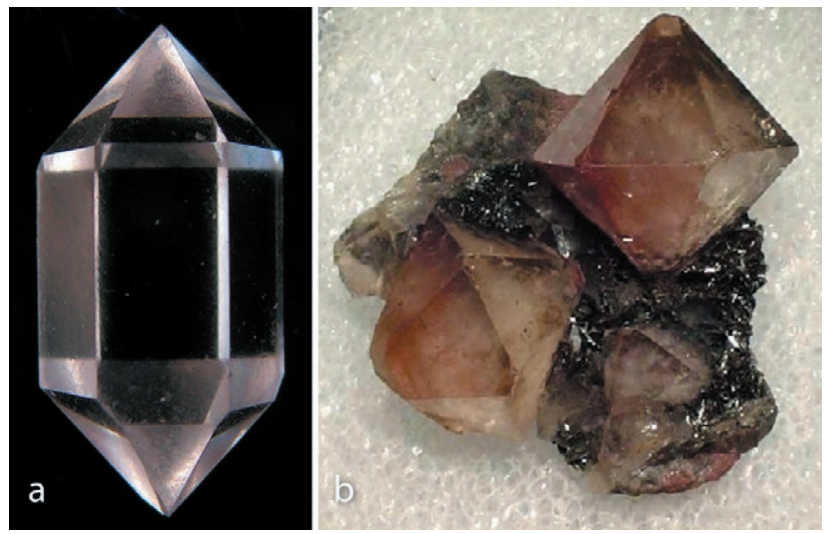

Fig. 7. Crystals of quartz. 7a: Quartz with typical habit. 7b: Quartz with "bipiramidal" habit (https://www.mindat.org/photo-188888. html; https://www.mindat.org/photo-156304.html).

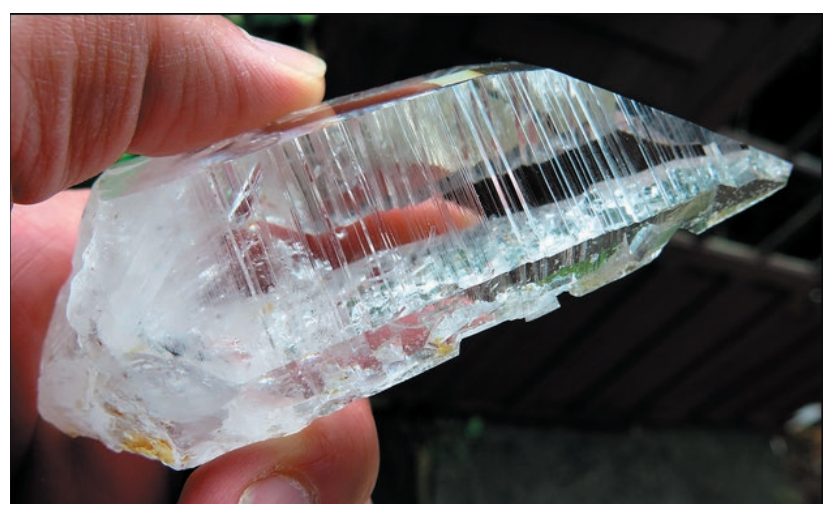

Fig. 8. Quartz crystal with striated faces (https://goldenhourminerals.com/listing/864704147/cristallo-naturale-colombiano-di-quarzo).

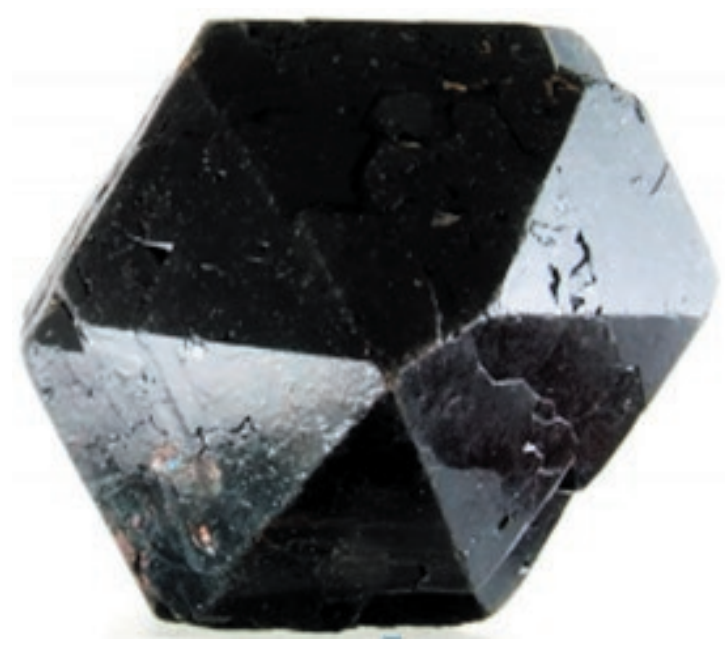

Fig. 9. Smoky quartz viewed perpendicular to the vertical axis (https://www.spiriferminerals.com $/$ mini.php?id=2654\&width=300\&file =gfa30d.jpg). 


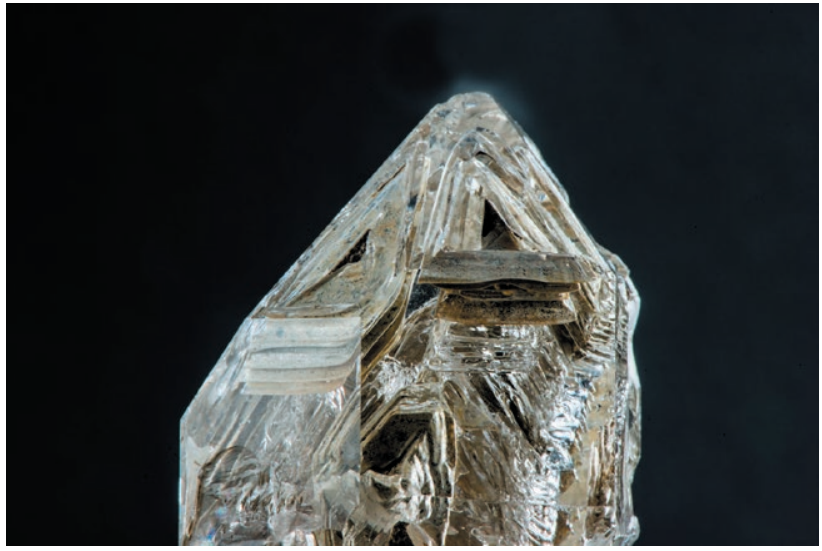

Fig. 10. Quartz: stepped crystal (https://sma.unibo.it/en/the-university-museum-network/mineralogical-collection-luigi-bombiccimuseum/gallery/).

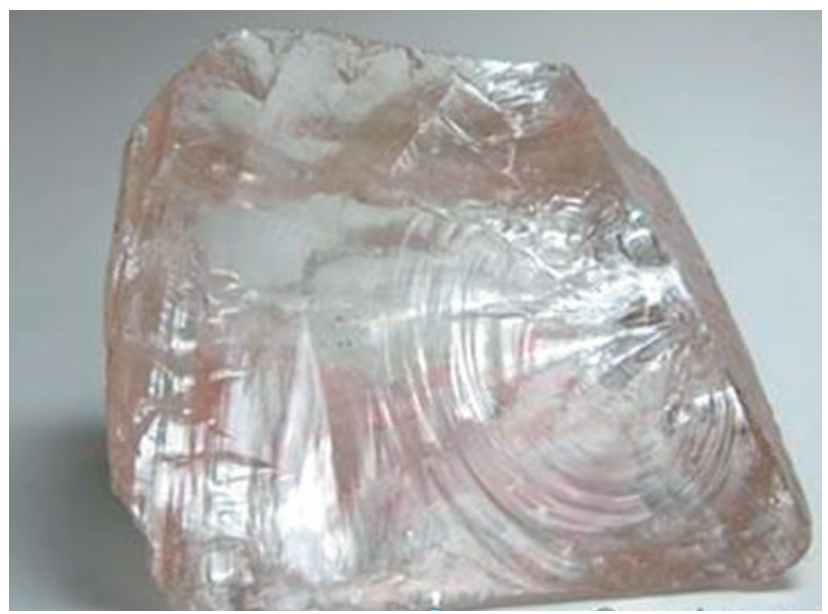

Fig. 11 Quartz: fracture surface (https://geology.com/minerals/ quartz.shtml).

edges develop more than the faces (Stenone [2], 1995, p. 27-28) (stepped crystals, Fig 10).

e) The hardening occurs at different times so the faces may not be completely smoothed. A fracture surface is smoother than the crystal faces (Stenone [2] $1995 \mathrm{p}$. 28) (Fig. 11).

f) Why does crystalline matter settle at one point of the growing crystal rather than another?

Steno writes that this depends on the characteristics of the growing crystal and not on those of the nutrient fluid (Stenone [2], p. 28-29).

\section{"Corpi angolati": Angular bodies}

After quartz (crystal), Steno deals with other angu- lar bodies, that is convex solids with interfacial angles; in particular hematite, diamond and pyrite.

With angular bodies of iron, he describes the various habits typical of hematite, namely rosettes (including micaceous hematite), "oligisto" with twelve faces and the crystals with 24 faces. Steno also investigates the way hematite is formed and grown in analogy to what was said for quartz. For diamond, in addition to the description of the various habits, he examines the analogies with the formation and growth of quartz and rejects the hypothesis that this mineral can re-form, in a few years, in the place from which it was extracted.

The marcasite (pyrite) that Steno deals with is always in cubes; it is likely that, as Mottana (in Stenone [2], p. $X V)$ observes, it was not a pyrite from Elba which, at least today, is mainly in pentagonal dodecahedra. Steno describes the perfection of cubic crystals (although in general Steno defines them as rectangular parallelepipeds because rarely faces are all the same), and the "trigliph" striated faces for which he finds a very complicated explanation linked to the movement of the fluid. Even the relationships with the rocky matrix are described with complex mechanisms for which he also refers to the "Magnus" Galileo. The end result, however, leads him to erroneously conclude that pyrite was formed before the embedding rock.

\section{Non mutatis angulis}

In Fig. 12, the upper part of the only image included in the Prodromus is shown. The first seven drawings represent vertical sections of a quartz crystal. In particular, section 1 (with four sides: a rhombus) refers to a crystal with a "bipyramidal" habit in which the column, i.e. the hexagonal prism, is completely absent (see Fig. 7b). In sections 2 and 3 (with six sides) the faces of the hexagonal prism do appear: in section 2 less developed than in 3 (see Fig. 7a). In section 4 irregularities appear in the faces such as the axes of the parts that make up the body of the crystal do not form a straight line. Sections 5 and 6 show that in the plane of the axis both the number and the length of the sides can change, while not changing the angles. Steno defines this characteristic with the three words (non mutatis angulis) which have become very famous. At the same time, several cavities remain in the center of the crystal and various little layers are formed. Finally, section 7 shows, always in the plane of the axis, the variation in the number and length of the sides when the new crystalline matter overlaps the faces of the "pyramids". The growth takes place layer by layer.

Drawings 8 to 12 show similar variations, but seen in sections perpendicular to the vertical axis. We pass 


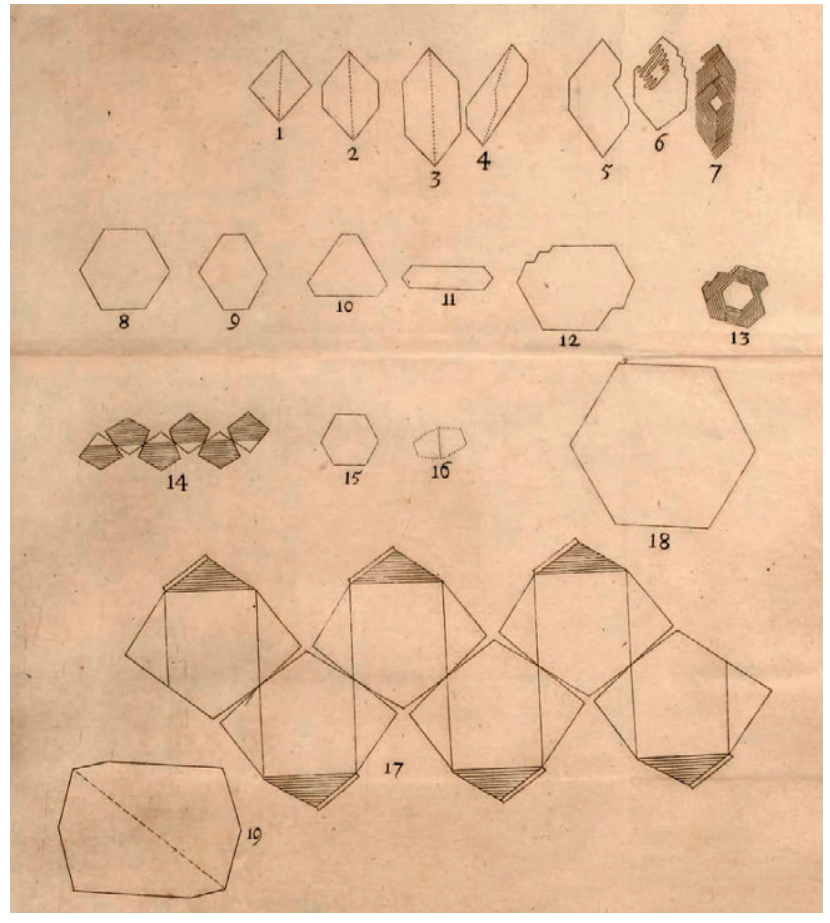

Fig. 12. Detail of plate published in Steno's Prodromus.

from a regular hexagon to figures with sides gradually different in length and then also in number.

Section 13 indicates how, when new matter is added on the face of the pyramids, sometime they change their length and the number of sides composing the base, but without changing the angles (non mutatis angulis).

The comparison between Steno's drawing and the result of modern X-ray investigations is impressive (Fig. 13).

Drawings 14 to 19 refer to the various types of hematite described in the text, and are a bit more complex. It should be noted that, for hematite, the sentence "non mutatis angulis" never appears.

As a curiosity we can add that Schneer ${ }^{13}$ notes that some of Steno's drawings, from his only illustration (Fig. 12), are similar to those of Hooke and he wonders if Steno may have been influenced by having perhaps seen Hooke's Micrographia during his stay in Paris. Of course the question is unanswered.

\section{CONCLUSIONS}

As we have already said, Steno could rely for mineralogy, crystallography and in general for the Earth

${ }^{13}$ C. J. Schneer, in Steno as geologist (Ed. G. Scherz), Odense, University Press Copenhagen, Acta Hist. Sci. Nat. Med, 1971, 23, p. 293-307.
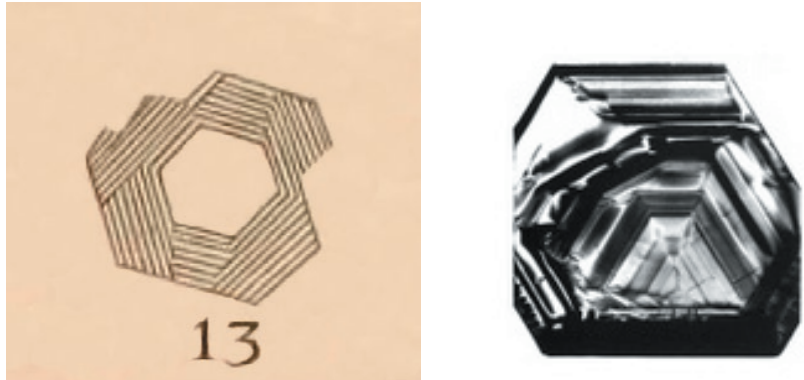

Fig. 13. Growth steps in a plane of quartz when seen down the c-axis. Left: enlargement of Steno's sketch (Stenone [2]; see Fig. 12). Right: X-ray topographic image of quartz exhibiting the typical dislocations and bands due to crystal growth (modified after Authier, $2013[3])$.

Sciences on the results published before him by scientists of considerable stature. As claimed by Authier [3] (p. 400), Steno was very familiar with the works of Kepler, Descartes, Bartholin and almost certainly Hooke too. However, these authors are never mentioned, perhaps because the Prodromus is a hasty text; perhaps they would have been mentioned in the "Dissertazione", which was never published. For example, the two crystallographic-groundbreaking concepts expressed by Steno, Non Mutatis Angulis and Crystal Growth (in particular quartz), had certainly some precursors in Biringucci, Kepler and Hooke. Democritus (Stenone [2], 1995, p. 3), Seneca (Stenone [2], 1995, p. 8), Hippocrates (Stenone [2], 1995, p. 16), Descartes (Stenone [2], 1995, p. 20) and Galileo (Stenone [2] 1995, p. 34) are mainly cited for philosophical reasons except Galileo mentioned in the discussion on the formation of pyrite, but with the wrong conclusion (certainly not because of Galileo) that pyrite was formed before the embedding rock.

It should never be forgotten that, mythological legacies, deep-seated superstitions and dogmatic bonds were still widespread and could also lead enlightened researchers to conclusions with no scientific value. An exemplary character to understand this mentality is Michele Mercati, a great scholar of rocks, minerals and fossils who was responsible for the "Vatican Metallotheca", the most important naturalistic museum of the Renaissance. In an interesting and exhaustive article entitled "Michele Mercati (1541-1593) e la Metallotheca", Accordi ${ }^{14}$ illustrates the theories of Mercati, basically a follower of Aristotle, who, in support of his theses, does not hesitate to report full passages of the Greek philosopher. Accordi ${ }^{14}$ (p. 12) writes: "By treating minerals he, like almost all his predecessors, fully accepts the theory

\footnotetext{
${ }^{14}$ B. Accordi, Geologica Romana, 1980, 19, pp. 1-50.
} 
of their genesis by condensation with the force of heat, or cold, in the presence or absence of air with or without the help of fire; therefore little progress since the time of Albert Magno (13th century)."Another singular aspect concerns citations of previous works. Accordi explains why Mercati, who cites the numerous sources he consulted, even though he publishes three drawings of the great Conrad Gesner (1515-1565), never cites him, as if he had never existed. Gesner was officially forbidden to Mercati as "heretic": he was a Protestant. It is worth remembering that Steno had the opportunity to read Mercati's manuscript (on Metallotheca) with the permission of the Florentine scholar and scientist Carlo Dati who had found and purchased it in $1665^{15}$.

Steno was usually able to eliminate these prejudices from his experimental way of inferring, but he was not always successful at eliminating them from the thoughts of others.

As suggested by Abbona ${ }^{16}$ in his extensive essay "Niccolò Stenone, un modello di ricercatore", we can refer to Steno's manuscript entitled Chaos (discovered only in 1946) as an important source of news about his personality. Steno writes: "In matters of natural sciences it is good not to bind to any theory, but to classify observations in order by trying to arrive at some result on one's own initiative. In the field of natural sciences we derive our knowledge only from experiments and observations and from all that we can detect with metaphysical and mechanical principles." And he continues "because nothing is more difficult than putting aside prejudices, even modern works are not free from traces of preconceived ideas, and if I wanted to make an exception, I would deserve censorship for my brazen pride" (quoted in Abbona [16], p. 68).

It is probable that also for this reason his lively and pragmatic Prodromus has fallen into oblivion for a long time, despite an English translation and a second edition in Latin (shortly after the first Florentine edition) printed in Leiden, home of the most ancient University of the Netherlands where Steno had followed courses in medicine, astronomy and others subjects.

However, there is no doubt that the Prodromus contains very remarkable observations also with regard to mineralogy and crystallography.

"Non mutatis angulis": as we have seen previously, these three words appear in the Explicatio figurarum about drawings 5 and 6 (longitudinal sections of quartz crystals). The same happens for drawing 13, the cross sectional drawing of a quartz crystal. Steno speaks about

\footnotetext{
${ }^{15}$ E. Andretta, Michele Mercati, Dizionario Biografico degli Italiani, 2009, 73.

${ }^{16}$ F. Abbona, Emmeciquadro 2004, 21, pp. 65-86.
}

the number and length of the sides, but it is clear that, being in section, it is about the number and extent of the faces and the non-changing angles are interfacial angles. Therefore for quartz the constancy of the dihedral angles is clearly established. A current formulation (derived from Carobbi's Mineralogy [5], p. 5) of the general law expressed by Romé de l'Isle in 1783 is the following: at the same temperature, crystals of the same crystalline substance, (however and wherever they are formed, if with a morphology similar) exhibit faces, determining in pairs (in all crystals) equal interfacial angles.

The three words of Steno (non mutatis angulis) have had, especially in the past, a very strong following; but can it be assumed that it is really a true anticipation of the first law of crystallography such as to attribute its authorship to Steno? According to Aloisi [10] (p. 165), this is not the case. "The observation is confined to the explanation of the table; in the text there is no mention of the thing and for the other minerals (oligisto, pyrite, diamond) both in the text and in the explanation of the figures, absolute silence in this regard".

It is interesting to compare Aloisi's opinion with that of Authier [3] (p. 399-400): "This is the only place where Steno clearly states the constancy of interfacial angles. He presents it as a fact of observation, without proof, and not as an universal law and he refrains from relating it to any atomistic hypothesis about the inner structure of the crystal."

Pedersen ${ }^{17}$ believes that this is essentially a philosophical problem; Steno limits himself to describing the constancy of the interfacial angles in quartz and implicitly in hematite. Pedersen continues (p. 123) "But it seems to be undeniable that Steno was the first scientist who put this insight to fruitful use even if he did not put it into relief as a fundamental law."

In conclusion, Biringucci, Libavius, Huygens, Hooke and others have expressed, for a single mineral, some ideas that, sometimes implicitly, lead to the concept of the constancy of the interfacial angles. Guglielmini represents a particular case as he deals with artificial salts; however his observations lead explicitly to the concept of the constancy of the angles at least for sodium chloride. Finally Steno's observations for quartz are precise and incontrovertible.

However, these are entirely confined to quartz and do not even extend explicitly to the other angular bodies (oligisto, pyrite, diamond) that Steno deals with. It therefore seems inappropriate to me to consider it a true anticipation of the universal law formulated by Romé de l'Isle.

${ }^{17}$ O. Pedersen, Stenoniana nova series Copenhagen, 1991, 1, pp. 113-134. 
"Crystal growth": his is truly Steno's most important intuition. The crystal grows from an initial germ (on whose nature Steno declares himself incompetent) by juxtaposition of particles precipitated by an external fluid. The growth takes place layer by layer; the growth speed is not the same for all faces; and the edges can grow faster than the faces. Crystalline matter is deposited in one point of the crystal instead of another due to the characteristics of the growing crystal and not those of the nutrient fluid.

As Dino Aquilano ${ }^{18}$ writes $(2014$, p. 3): "It is therefore to this Danish genius, naturalist, geologist and anatomist ....., that we owe the concept of anisotropy of the solid state, which distinguishes crystals from any other state of aggregation of matter."

Steno was also honoured with a mineral species dedicated after him in 1962. Stenonite is a rare aluminofluoride carbonate, $\mathrm{Sr}_{2} \mathrm{Al}\left(\mathrm{CO}_{3}\right) \mathrm{F}_{5}$, found and described by Pauly ${ }^{19}$ at the Ivigtut cryolite locality Greenland. The crystal structure of stenonite has been solved and published by Hawthorne ${ }^{20}$ in 1984.

\section{AKNOWLEDGEMENTS}

I thank Luca Bindi for helping with the English, Stefano Dominici for useful advice and Troels Kardel for providing bibliographic material difficult to find. The manuscript has benefited greatly from the revisions by A. Mottana, R. Rinaldi and G. D. Rosenberg.

\section{REFERENCES}

[1] O. Grubessi, F.P. Sassi, in Minerals in stamps (Eds. O. Grubessi, M. Pasero), Felici Editore, Pisa, 1998, viii $+215 \mathrm{pp}$.

[2] N. Stenone, Su un corpo solido contenuto naturalmente entro un altro solido. Prodromo a una Dissertazione, a cura di Annibale Mottana, Edizioni Teknos, Roma, 1995, p.66.

[3] A. Authier, Early days of X-ray crystallography, Oxford University Press, Oxford, 2013, $464 \mathrm{p}$.

[4] V. Biringucci, De la Pirotechnia a cura di A Mieli, Società Tipografica Editrice Barese, Bari, 1914, 198 p.

[5] F. Mazzi, G. P. Bernardini, I Fondamenti di Cristallografia e Ottica Cristallografica, in Mineralogia (Ed. Carobbi), USES, Firenze, 1983, 262 p.

\footnotetext{
${ }^{18}$ D. Aquilano, Emmeciquadro, 2014, 52, pp. 1-8.

${ }^{19}$ H. Pauly, Medd. Grønland, 1962, 169(9), pp. 1-24

${ }^{20}$ F. C. Hawthorne, Can. Mineralogist 1984, 22, 245-251.
}

[6] C. J. Schneer, Eur. J. Mineral., 1995, 7, pp. 721-734.

[7] J. Kepler, Strena seu de Nive Sexangula, Frankfurt am Main, Gottfried Tampach, 1611. English translation: C. Hardie with essays by B.G. Mason and L.L. Whyte, The six-sided snowflakes, Oxford University Press, Oxford, 1966.

[8] T. Hales, M. Adams, G. Bauer and 19 others $A$ formal proof of the Kepler conjecture, Forum of Mathematics, Pi, 2017, 5, e2, 29 pp., doi:https://doi. org/10.1017/fmp.2017.1.

[9] R. Hooke, Micrographia, Jo Martin, and Ja Allestry, printers to the Royal, Society, London, 1665.

[10] P. Aloisi, Periodico di Mineralogia, 1937, 8, pp. 163 175.

[11] T. Kardel,"Prompters of Steno's geological principles: Generation of stones in living beings, glossopetrae and molding," in The Revolution in Geology from the Renaissance to the Enlightenment (Ed. G. D. Rosenberg), Geological Society of America, Memoir 203, 2009 Boulder, CO., pp. 127- 134.

[12] F. Rodolico, Rivista Storia Scienze Mediche e Naturali, 1955, pp. 1-6.

[13] C. J. Schneer, in Steno as geologist (Ed. G. Scherz), Odense, University Press Copenhagen, Acta Hist. Sci. Nat. Med, 1971, 23, pp. 293-307.

[14] B. Accordi, Geologica Romana, 1980, 19, pp. 1-50.

[15] E. Andretta, Michele Mercati, Dizionario Biografico degli Italiani, 2009, 73.

[16] F. Abbona, Emmeciquadro, 2004, 21, pp. 65-86.

[17] O. Pedersen, Stenoniana nova series Copenhagen, 1991, 1, pp. 113-134.

[18] D. Aquilano, Emmeciquadro, 2014, 52, pp. 1-8.

[19] H. Pauly, Medd. Grønland, 1962, 169 (9), pp. 1-24.

[20] F. C. Hawthorne, Can. Mineralogist, 1984, 22, pp. 245-251. 